\title{
Human sensitivity to reinforcement in operant choice: How much do consequences matter?
}

\author{
SCOTT H. KOLLINS, M. CHRISTOPHER NEWLAND, and THOMAS S. CRITCHFIELD \\ Auburn University, Auburn, Alabama
}

\begin{abstract}
The results of many human operant conditioning experiments appear to show that humans are less sensitive than nonhumans to operant consequences, suggesting species discontinuities in basic behavioral processes. A reanalysis of 311 data sets from 25 studies employing variable-interval schedules of reinforcement designed to assess sensitivity to reinforcement corroborates the claim that human behavioral allocation among alternatives often deviates from predictions based on rates of experimentally programmed consequences. Close inspection of the studies in question, however, suggests that methodological issues contribute heavily to the differences noted so far between humans and nonhumans and that an explanation based upon species discontinuities is not tenable.
\end{abstract}

Consequences clearly influence the behavior of nonhuman organisms. The rich operant conditioning literature shows that reinforcing consequences alter the strength of behavior that produces them and forge relations between behavior and antecedent stimuli. These effects hold across a wide range of species, settings, response classes, and types of reinforcers, placing them among the most widely replicated outcomes in the biological and behavioral sciences. As a result, the threeterm operant contingency, which encompasses the relations among antecedent conditions, operant behavior, and reinforcers, has been proposed as the foundation of a broad range of complex capabilities both in nonhuman species (e.g., Donahoe, Burgos, \& Palmer, 1993) and, perhaps more speculatively, in humans (e.g., Skinner, 1953, 1957).

Successful applications to human affairs, based on the core notion that human behavior is sensitive to its consequences, provide reason for optimism about the generality of operant principles. As can be expected of a successful science, applications have flowed from the laboratory since the earliest days of operant psychology. They include, but are not limited to, animal models of substance abuse and treatment (e.g., Young \& Herling, 1986), behavior therapy (e.g., Ullmann \& Krasner, 1966), educational and behavioral interventions for persons with developmental disabilities (e.g., Lovaas, 1993), the management of problem behavior in educational settings (e.g., Mash \& Barkley, 1989), and strategies for enhancing performance in work settings (e.g., Daniels, 1994).

The systematic study of human behavior in the operant laboratory arose later than either the laboratory analysis

Portions of this material were presented at the annual meeting of the Southeastern Association for Behavior Analysis, Savannah, GA, October 1994, and at the annual meeting of the Association for Behavior Analysis, Washington, DC, May 1995. Correspondence should be directed to S. H. Kollins, now at the Department of Psychology, Western Michigan University. Kalamazoo, MI 49008-5052 (e-mail: kollish(a) fiona.umsmed.edu) of animal behavior or various endeavors in applied behavior analysis (e.g., Hyten \& Reilly, 1992). This work, which should have provided a natural bridge between animal work and application, instead produced several curious findings, most notable among which are failures to replicate outcomes common to the animal laboratory. For example, under simple schedules of reinforcement, human behavior often does not show finely differentiated response patterns, like the fixed-interval (FI) "scallop," that are widely regarded as standard indices of operant control in nonhuman performance (Baron, Perone, \& Galizio. 1991). Some have concluded that such discrepancies illustrate fundamental interspecies differences of behavior principles (e.g., Brewer, 1974), a conclusion that forces one to attribute a disturbing discontinuity to the human species (Buskist, Newland, \& Sherburne, 1991). Others. however, have argued that methodological considerations must be overcome before arriving at such a radical conclusion (Baron et al., 1991).

Whether humans and animals are affected similarly by the consequences of their actions is a compelling question, but response patterns under conventional schedules of reinforcement provide a poor test in this matter. Such response patterns have traditionally been evaluated through casual visual inspection of kymographic tracings (cumulative records) rather than through more reliable quantitative means, leaving their typicality open to dispute (Hyten \& Madden, 1993). Second, many instances of response patterns are the result of indirect variables operating under a reinforcement schedule and are not directly specified by the reinforcement. For example, the fixed-interval "scallop" is not specified in the schedule contingency but instead arises after much contact with the schedule and results from such subtleties as the selective reinforcement of moderate interresponse times and temporal discrimination in nonverbal subjects (see Zeiler, 1994, for an extended discussion).

The allocation of behavior across alternatives under concurrent schedules of reinforcement is a direct mea- 
sure of control of behavior by its consequences. Traditionally established in the laboratory through concurrent schedules of reinforcement, behavioral allocation in choice situations is readily quantified, and the process of quantification yields objective measures of sensitivity to reinforcing consequences (e.g., Baum, 1974; Davison \& McCarthy, 1988). Here we review the literature describing human behavior under concurrent schedules in laboratory settings, with particular attention devoted to the question of whether response allocation parallels that observed in nonhumans. We do identify differences but conclude that, pending new research, these can be attributed to idiosyncrasies in the way operant procedures have been adapted for use with humans at least as easily as to species discontinuities in the operation of behavioral principles.

\section{A Primer on Concurrent Schedules of Reinforcement}

Concurrent schedules permit two or more reinforcers to "compete" for behavior. In a typical arrangement with nonhumans, two response levers are available, each of which produces reinforcers according to separate and independent reinforcement contingencies. Reinforcement rates are the primary independent variables, and behavioral allocation (measured as ratios of either responses or time) across the schedules is the primary dependent variable. Variable interval (VI) schedules of reinforcement are commonly employed because they produce stable, moderate rates of responding and, unlike ratio-based schedules, do not constrain the relationship between response rates and reinforcement rates. Some experiments compare the relative control by two qualitatively different types of reinforcers, but when global sensitivity to reinforcement is of interest, everything (reinforcer quality, lever characteristics, etc.) is held constant across response alternatives except for the relative reinforcement rates provided by the alternatives, which are varied systematically. Sensitivity, then, is reflected in the extent to which relative responding tracks the relative reinforcement rates.

Nonhuman behavior under concurrent schedules is readily accounted for by the following equation:

$$
\log \left(B_{1} / B_{2}\right)=\mathbf{a} \log \left(r_{1} / r_{2}\right)+\log \mathbf{k},
$$

where the subscripts refer to response alternatives, $B_{1}$ and $B_{2}$ denote behavior on response alternatives 1 and $2, r_{1}$ and $r_{2}$ represent reinforcement rates on the two alternatives, and $\mathbf{a}$ and $\mathbf{k}$ are fitted parameters equaling the slope and intercept, respectively, of the function, which is linear in a $\log -\log$ coordinate space (Baum, 1974; Herrnstein, 1961, 1970). Behavior is usually measured as responses or time spent on an alternative. The upper panel of Figure 1 illustrates some possible outcomes of this quantitative relationship. A slope of 1 indicates that the behavior ratio $\left(B_{1} / B_{2}\right)$ tracks the reinforcement ratio in a one-to-one fashion. A slope greater than 1 ("overmatching") indicates that when the reinforcer ratio changes, the change in the behavior ratio exceeds that of the change in the reinforce-
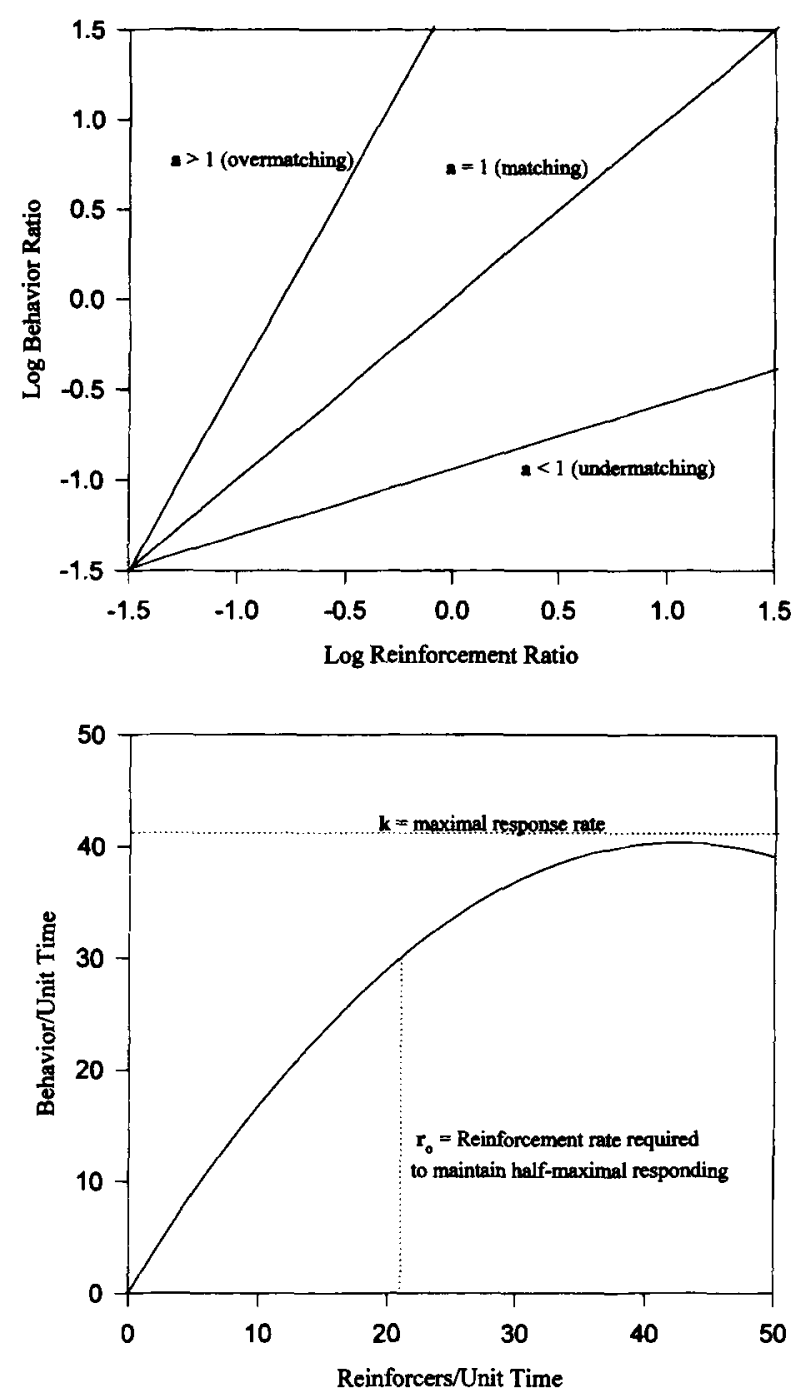

Figure 1. Examples of various outcomes for the mathematical functions described in Equations 1 and 2. Top panel: Variations in parameter a from Equation 1. This parameter is considered a measure of behavioral sensitivity to consequences. Bottom Panel: Example of function and parameters described by Equation $2 ; \boldsymbol{r}_{0}$ represents reinforcement necessary to maintain half-maximal responding, and $k$ represents the asymptote of the hyperbolic function and the maximum rate of responding.

ment ratio: behavior may be considered especially sensitive to the discrepancy between the two sources of reinforcement. Slopes less than 1 ("undermatching") indicate that when reinforcer ratios change, the ratio of the behavioral measures changes less than the change in reinforcer ratios: behavior may be considered relatively insensitive to discrepancies between the two sources of reinforcement. An extreme case of undermatching is a slope of 0 , in which behavior is utterly unaffected by variation in rates of consequences. In such a case, a strict application of the interpretation of the slope term, $\mathbf{a}$, indicates that behavior is insensitive to the discrepancy in consequences. A looser interpretation is that behavior is insensitive to the 
reinforcer, which is untenable if some behavior is occurring. Thus, it can be said that some consequences are maintaining responding but that the discrepancy between the rates on the two response alternatives is inert with respect to controlling behavior. It is relevant to note that, while we recognize the inability of all consequences to reinforce behavior, we will maintain use of the term "schedules of reinforcement" out of convention.

Equation 1 is related to another equation describing the monotonic relationship between response and reinforcement rate under a single schedule of reinforcement (Herrnstein, 1970):

$$
B=\mathbf{k} r / r_{0}+r .
$$

Here, $B$ and $r$ represent behavior (usually leverpressing) rate and reinforcement rate, respectively. The asymptote of the hyperbolic function, $\mathbf{k}$, has the units of responses/unit time and represents the maximum possible rate of responding. The other fitted constant, $r_{0}$, is in the unit of reinforcers/unit time and is often interpreted as representing all other reinforcers in the environment not produced by the arranged response. In this hyperbolic function, $r_{0}$ is the value that $r$ obtains when response rate reaches half of $\mathbf{k}$, or the half-maximal rate of reinforcement so $r_{0}$ scales alternative reinforcers in the units of programmed reinforcers. Equation 2 is important because it explicitly expresses the single-response situation as concurrent schedules in which the programmed reinforcer competes with other alternatives (grooming, exploring, "distractions"). Note that Equation 2 expresses the classic definition of a reinforcer (a consequence that elevates the likelihood of the response that produces it) in a context as defined by $r_{0}$.

Although there is disagreement as to whether Equations 1 and 2 represent fundamental or derived processes (Davison \& McCarthy, 1988; Herrnstein, 1970; Myerson
\& Hale, 1984; Ziriax, Snyder, Newland, \& Weiss, 1993), there is no dispute that the relationship depicted in Figure 1 is orderly and widely replicable in nonhuman species. Furthermore, there is wide consensus that the parameter $\mathbf{a}$ in Equation 1 (represented by the slope of the regression line in Figure 1) describes sensitivity of the behavior to the experimentally controlled consequences (Davison \& McCarthy, 1988; deVilliers, 1977). The concept of sensitivity to reinforcement represented by the parameter a has influenced research in a number of areas, including food preference (e.g., Heyman \& Monaghan, 1987), drug-taking behavior (e.g., Tucker, Vuchinich, \& Gladsjo, 1991), the impact of neurotoxicants on learning (Newland, Sheng, Lögdberg, \& Berlin, 1994), and signal detection (McCarthy \& Davison, 1981).

\section{Human Concurrent Schedule Performance}

Compared with the homogenous findings of nonhuman studies, the approximately 26 studies of human performance under VI schedules of reinforcement have produced mixed results. An understanding of the variables responsible for these results should broaden our understanding not only of human behavior, but also of similarities and differences observed between humans and nonhuman species. In addition, an understanding of the conditions under which quantitative models of choice describe human behavior will facilitate their application, at least on a conceptual level, to clinical and other nonlaboratory settings. The present review examines studies that have applied Equations 1 and 2 to human behavior in both laboratory and applied settings, and identifies several variables that appear to be associated with the sensitivity of human behavior to its consequences. We conclude with some speculation about the relevance of these findings with respect to future research and applications to human behavior.

Table 1

Laboratory Studies of Human Performance Under VI Schedules of Reinforcement

\begin{tabular}{|c|c|c|c|c|}
\hline Study & $\begin{array}{l}\text { Number of } \\
\text { Data Points }\end{array}$ & Schedule & Response & Consequence \\
\hline Baum, 1975 & 4 & CONC VI & Signal detection & $\begin{array}{l}\text { Noncontingent } \\
\text { money }\end{array}$ \\
\hline Bradshaw, Ruddle, Szabadi, 1981 & 12 & CONC VI & Lever pull & Points for money \\
\hline Bradshaw, Szabadi, 1978 & 6 & Single rate & Buttonpress & Points for money \\
\hline Bradshaw, Szabadi, Bevan, 1976 & 2 & CONC VI (Findley) & Buttonpress & Points for money \\
\hline Bradshaw, Szabadi, Bevan, 1977 & 3 & Single rate & Buttonpress & Points for money \\
\hline Bradshaw, Szabadi, Bevan, 1978 & 4 & Single rate & Buttonpress & Points for money \\
\hline Bradshaw, Szabadi, Bevan, 1979 & 6 & CONC VI (Findley) & Buttonpress & Points for money \\
\hline Bradshaw, Szabadi, Bevan, Ruddle, 1979 & 3 & CONC VI (Findley) & Buttonpress & Points for money \\
\hline Buskist, Miller, 1981 & 6 & CONC VI & $\begin{array}{l}\text { Vending machine } \\
\text { lever pull }\end{array}$ & Food \\
\hline Cliffe, Parry, 1980 & 6 & CONC VI & Buttonpress & Sexual slides \\
\hline Horne, Lowe, 1993 & 27 & CONC VI & Buttonpress & Points for money \\
\hline Navarick, Chellesen, 1983 & 12 & CONC VI (Findley) & Buttonpress & Points for money \\
\hline Ruddle, Bradshaw, Szabadi, Bevan, 1979 & 6 & CONC VI (Findley) & Lever pull & Points for money \\
\hline Schmitt, 1974 & 10 & CONC VI (Findley) & Buttonpress & Points for money \\
\hline Schroeder, Holland, 1969 & 6 & CONC VI & Eye movement & Signal detection \\
\hline Takahashi, Iwamoto, 1986 & 160 & CONC VI & Buttonpress & Points for money \\
\hline Wurster, Griffiths, 1979 & 6 & CONC VI (Findley) & Buttonpress & Points for money \\
\hline
\end{tabular}



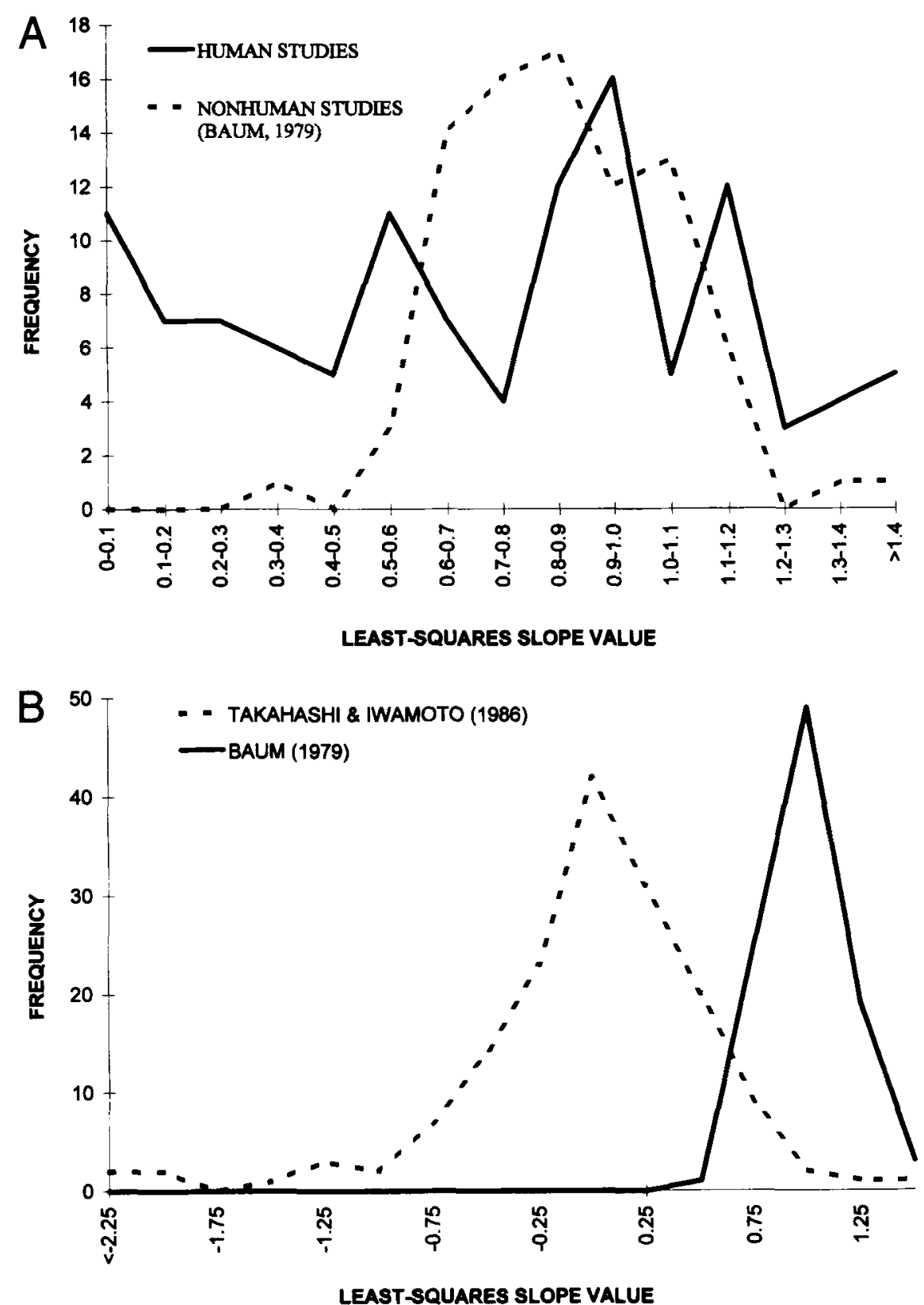

Figure 2. (A) Frequency distribution for slopes from human studies (solid line) and nonhuman studies (dashed line) reviewed by Baum (1979). (B) Frequency distributions of slopes for Takahashi and Iwamoto (1986) and Baum (1979).

\section{Human Sensitivity to Relative Reinforcement Rate: Laboratory Settings}

We located 17 studies that had investigated the performance of human subjects in laboratory settings under VI schedules of reinforcement (see Table 1). Of these 17 studies, 14 involved the use of concurrent VI-VI schedules to examine the matching relationship described in Equation 1. An additional three studies used the single-rate hyperbolic relationship described by Equation 2 (Bradshaw, Ruddle, \& Szabadi, 1981; Bradshaw, Szabadi, \& Bevan, 1977, 1978). Pierce and Epling (1983) reviewed many of the laboratory studies included in this count and concluded that "the matching law description of choice can be extended to an analysis of human behavior governed by alternative schedules of reinforcement" and that "the reviewed studies confirm matching under highly controlled conditions with interval schedules" (p. 72). These conclusions were mostly qualitative in nature, however, and several studies have been conducted since that time that cast doubt on the ubiquity of this phenomenon. A more recent, quantitative review (Bradshaw \& Szabadi, 1988) concluded that there had been substan- 
tial differences between human and nonhuman performance under apparently similar testing conditions, a conclusion that we do not dispute. Among these studies, however, no review to date has explored the contribution of procedural differences to the variability seen in the human data. Because the slope parameter, $\mathbf{a}$, in Equation 1 measures sensitivity to reinforcement, the present review focuses on slope values in human matching functions.

Figure 2A illustrates the distribution of 151 individual subject slope values from 13 of the 17 laboratory studies conducted since 1969. For comparison, Figure 1 also shows the distribution of 105 individual subject slope values derived from 23 nonhuman studies (reviewed by Baum, 1979). Note that although many nonhuman studies have been published in the past two decades, none challenges Baum's general conclusions, and thus Baum's review remains the benchmark summary of nonhuman concurrent-schedule performance. Three studies employing the single-rate form (Equation 2) and one, by Takahashi and Iwamoto (1986), employing concurrent schedules are not included in Figure 2. Because of the large number of individual data points (160) in the Takahashi and Iwamoto study, their data are considered separately in Figure 2B. The distribution of slopes was more variable from studies with humans than from studies using animals. The important benchmarks of this distribution point to a conclusion that humans are less sensitive to reinforcement discrepancies under concurrent schedules than nonhumans. First, the median value for humans was 0.70 , while that for nonhumans was 0.85 . Second, the first and third quartiles from the distribution representing slopes from human studies were 0.31-1.01, while those obtained from studies of nonhumans were $0.75-0.97$, indicative that much of the variability lay in the frequency of shallow slopes (extreme undermatching). Finally, slopes from studies of humans fell as low as 0.03 (complete insensitivity), while the lowest value in the nonhuman range was 0.38 . These benchmarks characterize what is evident in the shape of the distribution: the variability is at the left end of the distribution where undermatching becomes extreme. The slopes obtained by human subjects in Takahashi and Iwamoto (1986) also differed from those obtained by nonhuman species (reviewed by Baum, 1979). The median slope was -0.09 ; half of the slopes from this study were negative. The experimenters suggested that schedule discriminability was an important consideration in human matching under concurrent schedules.

The distributions of slopes from two sets of studies can be compared by comparing the important benchmarks. Differences between the distributions are summarized concisely in an empirical quantile-quantile (Q-Q) plot, which promotes visual and quantitative comparison of distributions (Chambers, Cleveland, Kleine, \& Tukey, 1983; Newland, in press). Empirical Q-Q plots are similar to the plots generated by many statistical packages to compare a distribution of data against a theoretical one, such as the normal distribution. The difference is that, in the $\mathrm{Q}-\mathrm{Q}$ plot, the horizontal axis is formed from an empiri- cally generated distribution and not a theoretical one. Hence, the Q-Q plot is nonparametric. As applied here, the $\mathrm{Q}-\mathrm{Q}$ plots constitute a form of meta-analysis of the quantitative relationship described in Equations 1 and 2, because they summarize information drawn from multiple studies. This application that the Q-Q plots will prove useful when we consider some possible reasons why human reinforcement-sensitivity parameters appear so scattered.

Figure 3 plots every 10 th percentile from the distribution of slopes taken from human studies shown in the slope distribution in Figure 2A plotted against the equivalent percentile from the nonhuman values. Values from studies of nonhumans appear on the abscissa and those from human studies are on the ordinate. For example, the location of the fifth data point represents the 0.5 quantile, the median. The coordinates of this point are $(0.85,0.70)$, indicating that the median for nonhumans $(0.85)$ is greater than that for humans $(0.70)$. The coordinates for the first two quartiles are $(0.75,0.30)$ and $(0.97,1.01)$. The major diagonal indicates the line on which the data would fall if the distributions were identical: the medians ( 0.5 quantiles) and all other quantiles would be equal. In this case, the slope of a regression line is 1 and the intercept is 0 . A regression line of greater than 1 using Q-Q plots indicates distributions that are unequal, and in this case human slopes are different from those of nonhumans. The slopes for nonhumans fall within a more restricted range $(0.66-1.07)$ but are closer to 1 than the slope values from humans $(0.07-1.26)$. A Kolmogorov-Smirnov test revealed that the distributions in Figure 2A were statistically different at the .05 level, but this analysis provides no description of the nature of the difference. Least-squares regression conducted on the $\mathrm{Q}-\mathrm{Q}$ plot is more informative than the KolmogorovSmirnov test, since it provides information about how

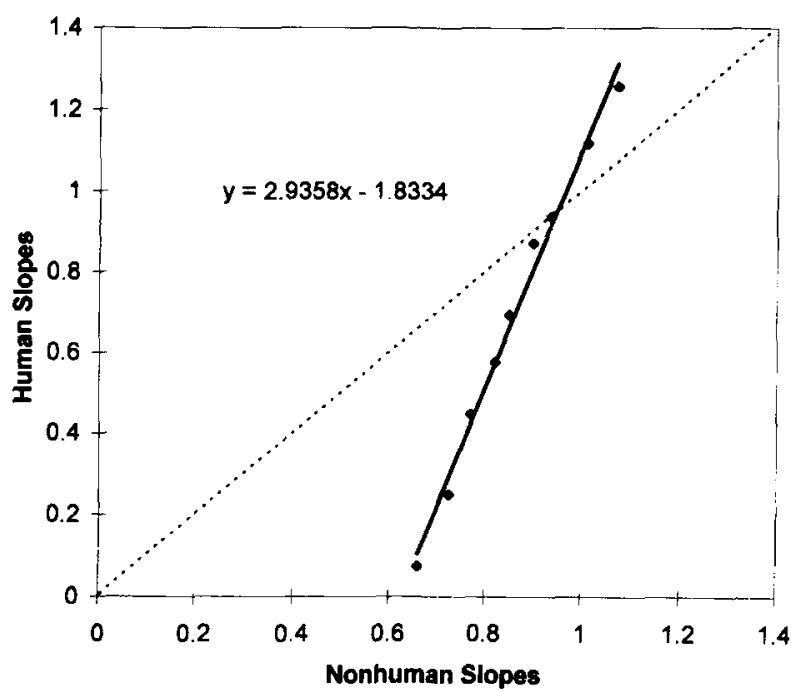

Figure 3. Empirical percentile-percentile plot of distributions of slopes from human studies ( $y$-axis) and nonhuman studies ( $x$ axis). See text for more explanation. 
the distributions actually differ. The greater-than- 1 slope in Figure 3 reflects the greater variability in the human studies shown on the vertical axis. The presence of a linear relationship between the distributions is consistent with some similarity in the shape and symmetry of the two distributions. The location of the intercept is sometimes difficult to interpret, but in general this term conveys information about where two distributions are most similar.

The distribution of slopes obtained from human matching studies is indeed different from that taken from nonhuman studies, but what accounts for the difference? Because procedural details often provide important clues about apparently discrepant data, we partitioned the human laboratory matching studies in three ways that are consistent with conventional thinking about operant choice and about operant methods in general. Each partition places the human studies into one of two categories defined by the status of a potentially important procedural variable (the type of response, the type of reinforcer, and the presence of explicit discriminative stimuli). We then represented each partition as an empirical Q-Q plot to assess whether and how the procedural factor contributed to variability in human matching. Our list of procedural factors is not meant to be exhaustive, but merely illustrative of factors that may influence the efficacy of potentially reinforcing consequences.

Response class. Responses measured in human concurrent-schedule studies include such diverse responses as eye movements, speech, and pulls on a vending machine door, but, perhaps out of experimenter convenience, the buttonpress has been used most (e.g., Shull \& Lawrence, 1991). Yet it has been suggested that because buttonpresses are part of many well-learned everyday performances (e.g., dialing the telephone), they may be especially susceptible to residual effects of prior reinforcement histories (Baron et al., 1991), and thus be less sensitive to the effects of recently introduced reinforcement in laboratory studies.

In Figure 4A, distributions were compared from human studies employing a buttonpress response versus those from studies employing other types of responses to determine whether response class contributed to the variability in slope estimates. The distribution of slopes from other-response studies ( $N=28$ individual-subject slopes) encompassed a smaller range (slope $>1$ ), tending to bunch around a value of 1.0 (intercept $>0$ ), than that from buttonpress studies $(N=81)$. The relationship described in Figure $4 \mathrm{~A}$ is linear, indicating a systematic difference between the studies in question, and the fitted line lies entirely below the major diagonal, indicating that, at all percentiles, slopes for those studies using other responses were higher than the studies using a standard buttonpress response. Consistent with prior speculation (Shull \& Lawrence, 1991), buttonpress responses are highly variable and generally appear to be less sensitive to consequences than other types of responses.

Type of consequences. Another possible cause for the discrepancy between human and nonhuman behavior under concurrent VI schedules of consequences is that the consequences with humans are not as reliably efficacious in controlling behavior as those used with nonhuman species (see, e.g., Wearden, 1988). One common experimental consequence, points exchangeable for money, has great surface appeal as a face-valid human reinforcer, especially in light of the fact that many subjects in human operant studies are college students presumably in need of money. Yet this consequence is subject to a number of criticisms, among which is the fact that delays ranging from days to months may separate the moment of point earning from the moment that points are converted to cash (Galizio \& Buskist, 1988; Hyten, Madden, \& Field, 1994). Furthermore, delays are known to devalue operant consequences (Myerson \& Green, 1995).

In Figure 4B, slope distributions from human studies employing points worth money as the reinforcer were compared with those from "studies"employing other types of reinforcers, including food, signal detection, and "sexually interesting" slides. Slopes from the latter category ( $N=22$ individual-subject slopes) were less variable (slope $>1$ ) and clustered more tightly around 1 than those from sidies employing points worth money as reinforcers $(N=81)$. A linear fit described the data well, and slopes tended to be higher when other consequences were used, indicating more effective reinforcement.

Discriminative stimuli. A compelling series of studies with nonhuman subjects shows that the discriminability between two sources of reinforcement plays a powerful role in the magnitude of the response ratio (reviewed in Davison \& McCarthy, 1988, chap. 11). When stimuli associated with each schedule are similar, the response rates on the two different schedules become more homogeneous. In most situations, this appears as undermatching. Furthermore, a number of researchers (Horne \& Lowe, 1993; Takahashi \& Iwamoto, 1986) have suggested that discriminative stimuli associated with different schedule values (e.g., a different colored light or symbol associated with each value of a series of VI schedules) may influence human sensitivity to consequences under such conditions.

Figure $4 \mathrm{C}$ indeed shows differences in distributions from studies employing schedule-correlated stimuli and studies employing no such explicitly controlled discriminative stimuli. The relationship between the two distributions is curvilinear, and the direction of the difference was the opposite of what might be expected. The shallow regression line in Figure 4C indicates a greater range of slopes for studies using discriminative stimuli (on the abscissa) than for the studies not employing such stimuli (on the ordinate). In the studies we examined, therefore, performance approximating matching was less reliable in the presence, rather than the absence, of discriminative stimuli.

Even studies without experimentally programmed discriminative stimuli may contain important unintended cues (e.g., location of operanda), meaning that the pro- 

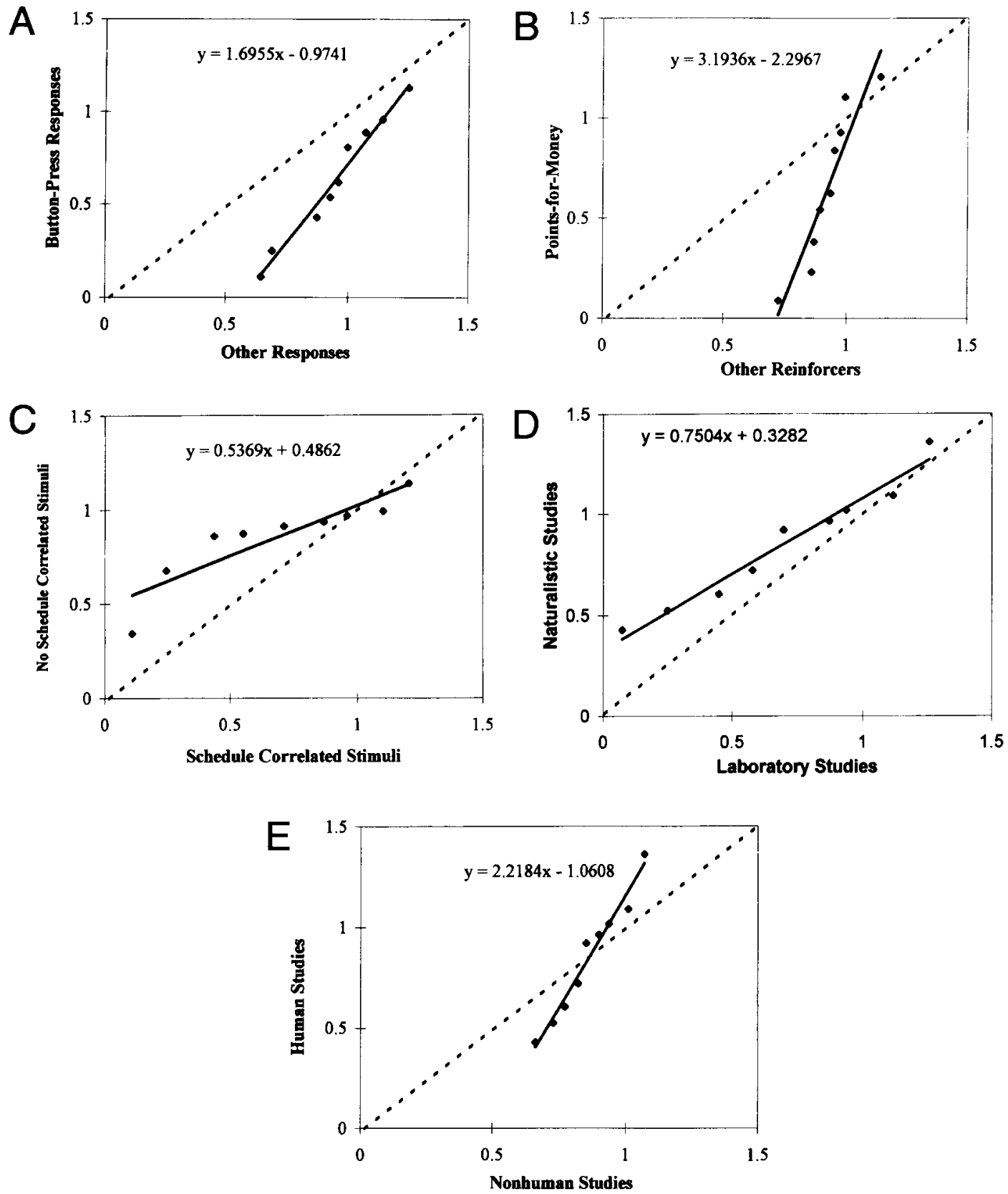

Figure 4. Comparison of slope distributions for human studies across of range of variables. (A) Buttonpress responses versus other responses. (B) Points for money versus other reinforcers. (C) Schedule-correlated stimuli versus no schedule-correlated stimuli. (D) Human laboratory studies versus human naturalistic studies. (E) Naturalistic human studies versus nonhuman studies.

cedural differences between studies could be more subtle than they would appear to be at first glance. Additionally, it is worth noting that 100 individual slope values were available from studies employing discriminative stimuli, while only 22 were available from studies employing no discriminative stimuli. Different numbers of observations in the distributions could have contributed to range differences. Nevertheless, the data in Figure 4C at least raise the possibility that discriminative stimuli matter in human matching, albeit possibly in unexpected ways, even if the nonlinearity of the fit renders any conclusion to be tentative.

Summary of laboratory studies. It appears that consequences other than points for money acquired better control over behavior. Either these are more effective reinforcers or better establishing operations were applied in studies using nonstandard reinforcers. In general, studies employing a simple buttonpress as a response 
class and those involving points for money as a consequence produced slopes relating response ratios to reinforcer ratios that varied over a very wide range. This may be because this response is unlikely to occur in the human's natural environment, although such an account is not satisfying since leverpresses or keypecks are not natural either. The variability could reflect methodological variables across studies, that is, a failure to achieve stability or to establish control over all elements of the three-term contingency of reinforcement. This interpretation corresponds to the findings of Takahashi and Iwamoto (1986), who showed that when discriminative stimuli and prior exposure to the contingencies under investigation were incorporated into the experiment, human behavior was more sensitive to consequences.

\section{Human Sensitivity to Relative Rate of Reinforcement: Naturalistic Studies}

In addition to the 17 studies that have been conducted under laboratory conditions, 8 studies have been conducted with humans in more naturalistic settings (Table 2). These have a direct bearing on the validity of the relationship described in Equations 1 and 2 in human behavior. Three of these employed concurrent VI-VI schedules (Conger \& Killeen, 1974; Mace, Neef, Shade, \& Mauro, 1994; Neef, Mace, Shea, \& Shade, 1992), while the others used Equation 2 to describe human behavior under VI schedules (Beardsley \& McDowell, 1992; Mace, McCurdy, \& Quigley, 1990; Martens, Halperin, Rummel, \& Kilpatrick, 1990; Martens \& Houk, 1989; Martens, Lochner, \& Kelly, 1992; McDowell, 1982). The table shows that studies in naturalistic settings employed a wide range of response classes and consequences. The most common class of consequences used in these studies was a form of social attention, while response classes included academic performance, verbal behavior, or social engagement.

To allow the single-response studies to be considered together with the concurrent-schedule studies in the Q-Q plots, a slope describing the relationship between response ratios and reinforcement ratios must be determined. $B_{1}$ and $r_{1}$ in Equation 1 are specified in the experiments, but $B_{2}$ and $r_{2}$ must be estimated as the rate of alternative, "other," responses and alternative reinforcers.
These were obtained from estimates of the parameters $\mathbf{k}$ and $r_{0}$ from Equation 2. Alternative responses were estimated by subtracting $B$ from $\mathbf{k}_{\max }$ (i.e., $B_{2}=\mathbf{k}_{\max }-B_{1}$ ) and alternative reinforcers were estimated as $r_{0}$. Data from the actual studies, when provided, served as values for $B_{1}$ and $r_{1}$. This led to a ratio of $B_{1} /\left(\mathbf{k}_{\max }-B_{1}\right)=r_{1} / r_{0}$.

Figure 4D shows that the distributions from these two groups of studies were less discrepant than those of other groups of studies shown in Figure 4. Although the two distributions were not significantly different from one another (Kolmogorov-Smirnov test), slopes from naturalistic studies encompassed a narrower range of values than did those from experimental studies. Only one value was less than about 0.40 , whereas in the laboratory $27 \%$ of the slopes fell below 0.40 . Figure $4 \mathrm{E}$ compares the results of naturalistic studies with those of nonhuman studies reviewed by Baum (1974). The median values are virtually identical, so the fitted line is symmetrical about the major diagonal. Unlike most of the distributions compared previously, the two distributions in Figure 4E have the same shape, although the distribution of human studies has more spread in the tails, since the only difference lies in how far the extreme ends of the distribution extend. In short, the results of these naturalistic studies closely approximate those of nonhuman studies, perhaps more so than do the results of human behavior under laboratory conditions. This is especially remarkable in view of the social nature of many of the consequences.

\section{Establishing Operations and Their Potential Role in Human Matching}

Because most studies differ procedurally in several ways, the binary comparisons conducted here are artificially simple in that they do not reflect the possible interaction among factors that could influence sensitivity to reinforcement. We chose to illustrate this discussion with comparisons representing each of the three terms in an operant contingency (antecedent stimuli, response, and consequence). Many other kinds of comparisons are possible, as the relevant studies differ procedurally on many dimensions. What all operant phenomena, including those in choice experiments, share is a fundamental reliance on the consequences of behavior. In this sense,

Table 2

Naturalistic Studies of Human Performance Under VI Schedules of Reinforcement

\begin{tabular}{|c|c|c|c|c|}
\hline Study & $\begin{array}{l}\text { Number of } \\
\text { Data Points }\end{array}$ & Schedule & Response & Consequence \\
\hline McDowell, 1981 & 1 & Single rate & Self-injurious behavior & Verbal reprimands \\
\hline Martens, Houk, 1989 & 4 & Single rate & $\begin{array}{l}\text { Classroom disruption } \\
\text { on-task behavior }\end{array}$ & Social attention \\
\hline Conger, Killeen, 1974 & Pooled & CONC VI & Verbal behavior & Social attention \\
\hline Martens, Lochner, Kelly, 1992 & 2 & Single rate & Academic engagement & Social praise \\
\hline Neef, Mace, Shea, Shade, 1992 & NA & CONC VI & Arithmetic problems & $\begin{array}{l}\text { Nickels andior } \\
\text { program money }\end{array}$ \\
\hline Beardsley, McDowell, 1988 & 6 & Single rate & Social engagement & Verbal praise \\
\hline Mace, McCurdy, Quigley, 1990 & NA & CONC VR & Arithmetic problems & Teacher attention \\
\hline Martens, Halperin, Rummel, Kilpatrick, 1990 & 10 & Single rate & On and off task behavior & Chips and candy \\
\hline
\end{tabular}


the comparisons we conducted are all related. Response classes are defined by the relationship between responses and reinforcers, and stimulus control results from the correlation between antecedent stimuli and the response-reinforcer relation (e.g., Rescorla, 1991; Skinner, 1938). It impossible to judge, therefore, which differences result directly from features of response classes or discriminative stimuli and which result indirectly from ineffective consequences. Put simply, discriminative stimuli and response classes are only as important as the reinforcers upon which they are created.

Given the centrality of consequences in operant behavior, its seems reasonable that any examination of sensitivity to reinforcement must start with a consideration of the consequences themselves. Our preceding discussion of the different classes of consequences makes clear that consequences matter, albeit not in the straightforward manner predicted by current quantitative models. The finding that naturalistic operant choice studies often produce animal-like data also is consistent with this conclusion, in the sense that such studies often employ different, and potentially more efficacious, events as consequences. A starting point for the integration of these findings may be found in the concept of the establishing operation (Michael, 1982, 1985), which is defined as "any change in the environment which alters the effectiveness of some object or event as reinforcement and simultaneously alters the momentary frequency of the behavior that has been followed by that reinforcement" (Michael, 1982, pp. 150-151). Difficulties with early reinforcement theories makes clear the error of considering reinforcers to be classes of events with stable properties (e.g., Meehl, 1951). A far more productive strategy is to consider the factors required to establish a given consequence as reinforcing (Michael, 1982, 1993; Timberlake \& Allison, 1974).

This review and an earlier one by Bradshaw and Szabadi (1988) both found that the results of human operant choice studies vary more widely than those of studies involving nonhuman subjects. Studies using many kinds of reinforcers have produced notably variable results in human species but, in contrast, compelling consistency across a variety of nonhuman species, orders, and types of reinforcment (Morse \& Kelleher, 1977). In this regard, it is worth suggesting that establishing operations typically are better controlled in studies with nonhuman subjects and that when they are controlled, the more refined patterns characteristic of different reinforcement contingencies may be revealed. Establishing operations that are related to physiological functioning such as food or water deprivation, temperature changes, and sexual reinforcement, or operations that are related to aversive events like electric shock or loud noise are most commonly employed and typically reveal refined scheduletypical patterns. In all of these cases, the means of establishing effective primary or secondary reinforcers are reasonably standardized and thus relatively invariant across studies. By contrast, many human operant-choice studies appear to be designed around the assumption that money, and the points that represent it during experiments, have already been established as reinforcers. The establishing operations remain largely unknown and thus could vary widely across individuals or across time for a given individual. This possibility is not unique to choice studies. Wearden (1988) has noted that, in general, studies using money as an incentive have produced evidence of individual differences in reinforcer efficacy. Moreover, from a choice perspective, one must always ask also how valuable other activities, which would appear as nonresponding in an operant study, might be to different individuals. This factor, too, could be expected to vary as the result of a variety of establishing operations (Wearden, 1988).

Some of the patterns described in the present review are easily interpreted in terms of establishing operations. It seems logical to assume, for example, that naturalistic studies tend to rely on consequences in the very environments where they naturally occur and thus in the presence of the establishing operations that make them naturally reinforcing. By contrast, in laboratory studies, points and money are relatively isolated from the everyday events that might make them reinforcing. For example, a number of studies have suggested that arranging a competitive situation alters points and money from mildly to strongly reinforcing (e.g., Buskist \& Miller, 1981). In fact, a variety of applied studies show that "points," in the sense of self-recorded counts of behavior, become more reinforcing when posted publicly than when made privately (e.g., Ciminero, Nelson, \& Lipinski, 1977; Cohen, Polsgrove, Reith, \& Heinen, 1981; Critchfield \& Vargas, 1991). In light of these findings, it is interesting to note that in many operant studies subjects work in isolation, with data recorded automatically, unobtrusively, and confidentially.

Another kind of establishing operation that could influence studies using points worth money as consequence was illustrated in a recent investigation of "selfcontrol" choices, in which subjects chose to work for either a small number of points awarded immediately or a larger number of points awarded several seconds later (Hyten et al., 1994). Points were exchangeable for money, and the amount of time before points became exchangeable was varied across experimental conditions. In general, subjects preferred the small, immediate reward when the "exchange delay" was short (e.g., 1 day) but preferred the larger, delayed reward when exchange delays were longer. Thus, the efficacy of the reinforcers interacted with exchange delays. It is well known that delays reduce the efficacy of reinforcers (e.g., Myerson \& Green, 1995), and this investigation provides a reminder that points worth money are not completely "consumed" at least until subjects have cash in hand. Interestingly, many reports of human operant research do not describe the process of exchanging points for money, but we suspect 
that these procedures vary across laboratories and across studies. It is possible that differences in exchange delays are responsible for some of the variability in human matching studies.

It remains entirely possible that the variability in reinforcement sensitivity seen in human operant choice studies reflects little more than variations in establishing operations, rather than something inherently unusual about humans. After all, studies that use points for money have not failed to produce matching in human subjects. Instead, these consequences have not consistently engendered behavioral allocation in the manner that might be expected from nonhuman studies. Not enough is known about the establishing operations that modulate the effectiveness of common laboratory consequences to support or refute this speculation, but the general importance of establishing operations to human choice should be easy to evaluate in studies that assess human operant choice, presumably in the same subjects, under a variety of levels of establishing operations. Perhaps the most easily implemented strategy would be to manipulate levels of food and water deprivation in nonhuman species that closely approximate matching under standard laboratory conditions. So far, it has been demonstrated that qualitatively different reinforcers (e.g., Heyman, 1994) clearly influence the parameters in Equation 1, as do differences in level of food deprivation (Heyman \& Monaghan, 1987).

For ethical and practical reasons, analogous investigations could be difficult to implement with respect to some reinforcers commonly used in human operant research. For example, it is hard to imagine how the operations establishing money as a reinforcer could be manipulated, especially as precisely as those establishing biologically important events as reinforcers. Establishing operations should be easier to manipulate for a variety of less commonly used consequences. For example, in a choice study not reviewed here, because it employed ratio schedules, subjects were placed in a cold room and could briefly activate a heat lamp by making either of two responses (Silberberg, Thomas, \& Berendzen, 1991). Under normal conditions, relative response rates approximately matched relative reinforcement rates. In this example, room temperature establishes heat as a reinforcer, and it would be a simple matter to manipulate room temperature across experimental conditions.

Another possibility involves the use of drugs as reinforcers for substance-dependent individuals. For example, in a number of nonchoice studies, regular users of caffeine and nicotine have agreed to suspend their drug intake temporarily except for doses earned contingent on performance in a research study (e.g., Evans, Critchfield, \& Griffiths, 1991). There is no reason, in principle, why these reinforcers could not be incorporated into concurrent schedule procedures in which level of deprivation (time since the last dose) is manipulated within subjects.

Both of the preceding examples may be thought of as avoidance procedures in which the reinforcer terminates or postpones an aversive event. Other avoidance procedures provide similar opportunities for manipulating establishing operations. For example, when responses lead to the reduction of such aversive events as noise or pain, the magnitude of the aversive event often is readily manipulable for individual subjects.

For purposes of generality testing, it may be useful to extend investigations of establishing operations in human operant choice to include operations that are not easily manipulable but which can be investigated in betweensubjects comparisons. For example, it should be possible to screen potential subjects to locate individuals with different income-to-expenses ratios and who therefore presumably have different money needs. Matching functions could then be compared across groups of subjects. A similar opportunity is suggested by Cliffe and Parry`s (1980) choice study, in which sexually explicit photographs served as reinforcers for sexual offenders (the study produced close approximations of matching). It should be possible to locate groups of individuals for whom the appeal of sexual stimuli obviously varies, and to compare matching functions across groups.

Certain clinical syndromes may even provide the opportunity for naturally occurring "experiments" involving establishing operations. For example, persons with bipolar disorder may experience periods of "normal" mood but also cycle between states in which hedonic processes presumably are increased (manic) and decreased (depressed) compared with normal. In one investigation. two patients with bipolar disorder worked on a variety of VI schedules during normal, manic, and depressed states (Bradshaw \& Szabadi, 1978). Herrnstein's (1970) singleresponse equation (Equation 2) fit the functions in all three states equally well, but sensitivity to reinforcement increased during manic phases and decreased during depressed phases.

Another approach to examining the role of establishing operations that could be taken is to manipulate the level of food and water deprivation in nonhuman species that otherwise closely approximate matching. Parametric manipulation of deprivation (e.g., water deprivation of $23,16,8$, and $0 \mathrm{~h}$ ) might reveal important changes in behavioral allocation across concurrently available alternatives with water-access as a consequence.

Determining the role that these establishing operations play in human matching behavior may begin to explain variability among human studies and between human and nonhuman studies. Additionally, consideration of human establishing operations increases our chances of effectively applying matching theory to clinical settings. It is likely that the reason naturalistic matching studies with humans have produced results more consistent with matching is that the conditioned establishing operations in these studies have rendered the consequences more effective via verbal histories. For example, at first glance, the consequence of social praise used in several naturalistic studies seems to be not much different from points for money in the laboratory. The operations in place in a classroom setting, and in our soci- 
ety in general, have established social praise as a potent reinforcer.

\section{Applications and Directions for Future Research}

The present analyses suggest three variables that are important in producing sensitivity to consequences in human behavior: the type of response class, the type of consequence, and the discriminability of the reinforcement schedule. Because our analyses compared data across studies, these possibilities await systematic investigation within experiments. Apparently only two studies directly support the importance of discriminative stimuli in establishing control over human behavior by relative rate of consequences (Horne \& Lowe, 1993; Takahashi \& Iwamoto, 1986), but studies from nonhuman species are persuasive (Davison \& McCarthy, 1988). To our knowledge, no human studies have systematically examined the influence of response class, type of consequence, or the relationship between establishing operations and consequences upon human behavior under VI schedules.

As our understanding of the variables that modulate control of human behavior by consequences increases, so too will our ability to use the relations in Equations 1 and 2 effectively in applied settings (see Martens \& Houk, 1989; McDowell, 1982). Determining the extent to which discriminable sources of reinforcement gain control over human behavior, identifying more effective consequences, or creating environments where consequences can be established as effective reinforcers, can only improve the utility of interventions in applied settings. Relatedly, a more thorough understanding of "typical" concurrent schedule performance in humans may contribute to our understanding and conceptualization of behavior problems. For example, it has been demonstrated that behavioral allocation under concurrent schedules in children diagnosed with attention deficit hyperactivity disorder differs from that of normal children with respect to relative sensitivity to reinforcement (Kollins, Lane, \& Shapiro, 1997). Determining whether this difference was related to the efficacy of the reinforcer used, the ability of the stimuli associated with the schedule to control behavior, or to the relationship between establishing operations and consequences may contribute to the development of more effective interventions.

The arrangements used in laboratory studies of human operant behavior sometimes do not gain control over behavior. It is wrong to conclude from this lack of control that consequences necessarily are irrelevant to human behavior or participate in ways different from those seen with nonhuman species. The present analyses show that, under some conditions, human behavior resembles very closely that of nonhuman species. Under others, it does not. It is more accurate to conclude that, in any species, not all consequences are reinforcing, and that those that function as reinforcers do not do so equally in all situations. The mere application of a consequence, even if it is "intuitively" reinforcing, may not be sufficient in establishing control over behavior. The proper selection of consequences and the arrangement of establishing operations are essential. A failure to replicate the three-term contingency in human species may not indicate that humans are fundamentally different from other species. Instead, some failures say more about the conditions under which human behavior has been studied than about the behavior under investigation. Before drawing conclusions regarding interspecies variation in behavioral process, we should strive for a more thorough understanding of how the procedures used to study behavior-of all species, but especially of humans - affect the behavior under question.

\section{REFERENCES}

Baron, A., Perone, M., \& Galizio, M. (1991). Analyzing the reinforcement process at the human level: $C$ an application and behavioristic interpretation replace laboratory research? Behavior Analyst, 14 , 95-105.

BAUM, W. M. (1974). On two types of deviation from the matching law: Bias and undermatching. Journal of the Experimental Analysis of Behavior, 22, 231-242.

BAUM, W. M. (1975). Time allocation in human vigilance. Journal of the Experimental Analysis of Behavior, 23, 45-53.

BAUM, W. M. (1979). Matching, undermatching, and overmatching in studies of choice. Journal of the Experimental Analysis of Behavior, 32, 269-281.

Beardsley, S. D., \& MCDowell, J. J. (1992). Application of Herrnstein's hyperbola to time allocation of naturalistic human behavior maintained by naturalistic social reinforcement. Journal of the Experimental Analysis of Behavior, 57, 177-185.

Bradshaw, C. M., Ruddle, H. V., \& Szabadi, E. (1981). Studies of concurrent performances in humans. In C. M. Bradshaw. E. Szabadi, \& C. F. Lowe (Eds.), Quantification of steady-state operant behavior (pp. 132-149). Amsterdam: Elsevier, North-Holland.

Bradshaw, C. M.. \& Szabad, E. (1978). Changes in operant behavior in a manic-depressive patient. Behavior Therapy, 9, 950-954.

Bradshaw, C. M., \& SzaBadi, E. (1988). Quantitative analysis of human operant behavior. In G. Davey \& C. Cullen (Eds.), Human operant conditioning and behavior modification (pp. 225-259). London: Wiley.

Bradshaw, C. M., Szabadi, E., \& Bevan, P. (1976). Behavior of humans in variable-interval schedules of reinforcement. Journal of the Experimental Analysis of Behavior, 26, 135-141.

Bradshaw, C. M., Szabadi, E.. \& Bevan, P. (1977). Effect of punishment on human variable-interval performance. Journal of the Experimental Analysis of Behavior, 27, 275-279

Bradshaw, C. M., Szabadi, E., \& Bevan, P. (1978). Effect of variableinterval punishment on the behavior of humans in variable interval schedules of monetary reinforcement. Journal of the Experimental Analysis of Behavior, 29,161-166.

Bradshaw, C. M., Szabadi, E., \& Bevan, P. (1979). The effect of punishment on free-operant behavior in humans. Joumal of the Experimental Analysis of Behavior, 31, 71-81.

Bradshaw, C. M.. Szabadi, E., Bevan, P., \& Ruddi.e. H. V. (1979). The effect of signalled reinforcement availability on concurrent performances in humans. Journal of the Experimental Analysis of Behavior, 32, 65-74.

BREWER. W. F. (1974). There is no convincing evidence for operant or classical conditioning in adult humans. In W. B. Weimer \& D. S. Palermo (Eds.), Cognition and the symbolic processes (pp. 1-33). Hillsdale, NJ: Erlbaum.

Buskist, W., \& Miller. H. (1981). Concurrent operant performance in humans: Matching when food is the reinforcer. Psichological Record, 31, 95-100.

Buskist, W., Newland, M. C., \& Sherburne, T. (1991). Continuity and context. Behavior Analvst, 14,111-116.

Chambers, J. M.. Cleveland, W. S., Kleine, B., \& Tukey, P. A. (1983). Graphical methods for data analvsis. Belmont, CA: Wadsworth. 
Ciminero, A. R., Nelson, R. O., \& Lipinski, D. P. (1977). Self-monitoring procedures. In A. R. Ciminero, K. S. Calhoun, \& H. E. Adams (Eds.), Handbook of behavioral assessment (pp. 195-233). New York Wiley.

Cliffe, M. J., \& PARry, S. J. (1980). Matching to reinforcer value Human concurrent variable interval performance. Quarterly Journal of Experimenial Psychology, 32, 557-570.

Cohen, R., Polsgrove, L., Reith, H., \& Heinen, J. R. K. (1981). The effects of self-monitoring, public graphing, and token reinforcement on the social behaviors of underachieving children. Education \& Treatment of Children, 4, 125-138.

CONGER, R., \& KilleEN, P. (1974). Use of concurrent operants in small group research. Pacific Sociological Review, 17, 399-416.

Critchfield, T. S., \& Vargas, E.A. (1991). Self-recording, instructions, and public self-graphing: Effects on swimming in the absence of coach verbal interaction. Behavior Modification, 15, 95-112.

DANIElS, A. C. (1994). Bringing out the best in people. New York. McGraw-Hill.

Davison, M., \& MCCARThy, D. (1988). The matching law. Hillsdale, NJ: Erlbaum.

DEVILliERS, P. A. (1977). Choice in concurrent schedules and a quantitative formulation of the law of effect. In W. K. Honig \& J. E. R. Staddon (Eds.), Handbook of operant behavior (pp. 233-287). Englewood Cliffs, NJ: Prentice-Hall.

Donahoe, W., Burgos, J., \& Palmer, D. (1993). A selectionist approach to reinforcement. Journal of the Experimental Analysis of Behavior, 60, 17-40

Evans, S. M., Critchfield, T. S., \& Griffiths, R. R. (1991). Abuse liability assessment of anxiolytics/hypnotics: Rationale and laboratory lore. British Journal of Addictions, 86, 1625-1632.

GaLIZIO, M., \& BuSKIST, W. F. (1988). Laboratory lore and research practices in the experimental analysis of human behavior: Selecting reinforcers and arranging contingencies. Behavior Analyst, 11, 65-69.

HERRNSTEIN, R. J. (1961). Relative and absolute strength of response as a function of frequency of reinforcement. Journal of the Experimental Analysis of Behavior, 4, 267-272.

HERRNSTEIN, R. J. (1970). On the law of effect. Journal of the Experimental Analysis of Behavior, 13, 243-266.

HEYMAN, G. (1994). Reinforcer magnitude (sucrose concentration) and the matching law theory of response strength. Journal of the Experimental Analysis of Behavior, 61, 505-516.

Heyman, G., \& Monaghan, M. (1987). Effects of changes in response requirement and deprivation on the parameters of the matching law equation: New data and review. Journal of Experimental Psychology: Animal Behavior Processes, 13, 384-394.

Horne, P. J., \& Lowe, C. F. (1993). Determinants of human performance on concurrent schedules. Journal of the Experimental Analysis of Behavior, 59, 29-60.

Hyten, C., \& MAdDEN, G. J. (1993). The scallop in human fixed interval research: A review of problems with data description. Psychological Record, 43, 471-500.

Hyten, C., Madden, G. J., \& Field, D. P. (1994). Exchange delays and impulsive choice in adult humans. Journal of the Experimental Analysis of Behavior, 62, 225-232.

Hyten, C., \& Reilly, M. P. (1992). The renaissance of the experimental analysis of human behavior, Behavior Analyst, 15, 109-114.

Kollins, S. H., Lane. S. D., \& ShaPIRO, S. K. (1997). Experimental analysis of childhood psychopathology: A laboratory matching analysis of the behavior of children diagnosed with attention deficit hyperactivity disorder (ADHD). Psychological Record, 47, 25-44.

LovaAs, O. I. (1993). The development of a treatment research project for developmentally delayed and autistic children. Journal of Applied Behavior Analysis, 26, 617-630.

Mace, F. C., McCurdy, B., \& Quigley, E. A. (1990). A collateral effect of reward predicted by matching theory. Journal of Applied Behavior Analysis, 23, 187-205.

Mace, F. C., Neef, N. A., Shade, D., \& Mauro, B. C. (1994). Limited matching on concurrent schedule reinforcement of academic behavior. Journal of Applied Behavior Analysis, 27, 585-596.

Martens, B. K., Halperin, S., Rummel, J., \& Kilpatrick, D. (1990). Matching theory applied to contingent teacher attention. Behavioral Assessment. 12, 139-155.
MARTENS, B., \& Houk, J. (1989). The application of Herrnstein's law of effect to disruptive and on-task behavior of a retarded adolescent girl. Journal of the Experimental Analysis of Behavior, 51, 17-27.

Martens, B. K., Lochner, D. G., \& Kelly, S. Q. (1992). The effects of variable-interval reinforcement on academic engagement: $A$ demonstration of matching theory. Journal of Applied Behavior Analysis, 25, 143-151.

MASH, E. J., \& BARKLEY, R. A. (1989). Treatment of childhood behavior disorders: A behavioral perspective. New York: Guilford.

MCCARThy, D., \& Davison, M. (1981). Signal detection and matching. In M. L. Commons \& J. A. Nevin (Eds.), Quantitative analysis of behavior (Vol. 1, pp. 393-417). Cambridge, MA: Ballinger.

MCDowell, J. J. (1982). The importance of Herrnstein's mathematical statement of the law of effect for behavior therapy. American Psychologist, 37, 771-779.

MeEhl, P. E. (1951). On the circularity of the law of effect. Psychological Bulletin, 47, 52-75

MiChaEL, J. (1982). Distinguishing between discriminative and motivational functions of stimuli. Journal of the Experimental Analysis of Behavior, 37, 149-155.

MichaEl, J. (1993). Establishing operations. Behavior Analyst. 16. 191-206

Morse, W. H., \& Kelleher, R. T. (1977). Determinants of reinforcement and punishment. In W. K. Honig and J. E. R. Staddon (Eds.), Handbook of operant behavior (pp. 174-200). Englewood Cliffs, NJ: Prentice-Hall.

Myerson, J., \& Green, L. (1995). Discounting of delayed rewards: Models of individual choice. Journal of the Experimental Analysis of Behavior, 64, 257-262.

Myerson, J., \& Hale, S. (1984). Practical implications of the matching law. Journal of Applied Behavior Analysis, 17, 367-380.

NAVARICK, D. J. \& Chellsen, J. (1983). Matching versus undermatching in the choice behavior of humans. Behaviour Analysis Letters, 3 , 325-335.

Neef, N., Mace, F. C., Shea, M., \& Shade, D. (1992). Effects of reinforcer quality on time allocation: Extensions of matching theory to educational settings. Journal of Applied Behavior Analysis, 25, 691-699.

Newland, M. C. (in press). Quantifying the molecular structure of behavior: Separate effects of caffeine, cocaine, and adenosine agonists on interresponse times and lever-press durations. Behavioural Pharmacology.

Newland, M. C., Sheng, Y., Lögdberg, B., \& Berlin, M. (1994). Prolonged behavioral effects of in utero exposure to lead or methylmercury: Reduced sensitivity to changes in reinforcement contingencies during behavioral transitions and in steady state. Toxicology \& $A p$ plied Pharmacology, 126, 6-15.

PierCE, W. D., \& EPLING, W. F. (1983). Choice, matching, and human behavior: A review of the literature. Behavior Analyst, 6, 57-76.

RESCORLA, R. A. (1991). Associations between an instrumental discriminative stimulus and multiple outcomes. Journal of Experimental Psychology: Animal Behavior Processes, 18, 95-104.

Ruddle, H., Bradshaw, C. M., Szabadi, E., \& Bevan, P. (1979). Behaviour of humans in concurrent schedules programmed on spatially separated operanda. Quarterly Journal of Experimental Psychology. 31, 509-517.

SchmitT, D. R. (1974). Effects of reinforcement rate and reinforcer magnitude on choice behavior of humans. Journal of the Experimental Analysis of Behavior, 21, 409-419.

Schroeder, S. R., \& Holland, J. G. (1969). Reinforcement of eye movement with concurrent schedules. Joumal of the Experimental Analysis of Behavior, 12, 897-903.

Shult, R. L., \& Lawrence, P. S. (1991). Preparations and principles. Behavior Analyst, 14, 133-138.

Silberberg, A., Thomas, J. R., \& Berendzen, N. (1991). Human choice on concurrent variable interval variable ratio schedules. Journal of the Experimental Analysis of Behavior, 56, 575-584.

SKINNER, B. F. (1938). The behavior of organisms. New York. AppletonCentury-Crofts.

SkinNer, B. F. (1953). Science and human behavior. New York Macmillan.

Skinner, B. F. (1957), Verbal behavior. New York: Appleton-CenturyCrofts. 
Takahashi, M., \& IWamoto, T. (1986). Human concurrent performances: The effects of experience, instructions, and schedule correlated stimuli. Journal of the Experimental Analysis of Behavior, 45, 257-267.

Timberlake, W., \& Allison, J. (1974). Response deprivation: An empirical approach to instrumental performance. Psychological Review, 81, 146-164.

Tucker, J. A., Vuchinich, R. E., \& Gladsjo, J. A. (1991). Environmental influences on relapse in substance use disorders. International Journal of the Addictions, 25, 1017-1050.

Ullmann, L. P., \& Krasner, L. (1966). Case studies in behavior modification. New York: Holt, Rinehart \& Winston.

WEARDEN, J. H. (1988). Some neglected problems in the analysis of human behavior. In G. Davey \& C. Cullen (Eds.), Human operant conditioning and behavior modification (pp. 197-224). Chichester, U.K.: Wiley.
WURSTER, R. M., \& GRIfFITHS, R. R. (1979). Human concurrent performances: Variation of reinforcer magnitude and rate of reinforcement. Psychological Record, 29, 341-354

Young, A. M., \& Herling, S. (1986). Drugs as reinforcers: Studies in laboratory animals. In S. R. Goldberg \& I. P. Stolerman (Eds.), Behavioral analysis of drug dependence (pp. 9-67). Orlando, FL: Academic Press.

ZEILER, M. D. (1994). Temporal control in fixed-interval schedules Journal of the Experimental Analysis of Behavior, 61, 1-9.

ZiriaX, J. M., SNyder, J. R., Newland, M. C., \& Weiss, B. (1993). Amphetamine modifies the microstructure of concurrent behavior. Experimental \& Clinical Psychopharmacology, 1, 121-132.

(Manuscript received December 20, 1996: revision accepted for publication February 24, 1997.) 